\title{
DEGRADATION KINETICS OF ANTHOCYANINS DURING HEAT TREATMENT OF WILD BLACKTHORN (Prunus spinosa L.) FRUITS EXTRACT
}

\section{BIANCA MOLDOVAN ${ }^{\mathrm{a}}$, ANAMARIA ARDELEAN ${ }^{\mathrm{a}}$, LUMINITSA DAVID ${ }^{\mathrm{a}}$}

\begin{abstract}
The blackthorn (Prunus spinosa L.) fruits are known as a valuable source of anthocyanins and for their high antioxidant capacity. The aim of the present study was to investigate the thermal stability of anthocyanins from blackthorn fruits, at different temperatures $\left(2^{\circ} \mathrm{C}, 20^{\circ} \mathrm{C}\right.$ and $75^{\circ} \mathrm{C}$ ) and to determine the kinetic and thermodynamic parameters of their degradation reactions. Data analysis indicated a first-order reaction kinetics for the degradation of blackthorn anthocyanins at various temperatures. Kinetic parameters, such as reaction rate constant $k$, half-life $t_{1 / 2}$, and activation energy Ea values were determined. The obtained results indicated that blackthorn anthocyanins stored at $2^{\circ} \mathrm{C}$ exhibited the highest stability, the degradation constant rate being $5.0 \cdot 10^{-4} \mathrm{~h}^{-1}$. The activation energy of the thermal degradation was also determined and was found to be $53.96 \mathrm{~kJ} / \mathrm{mol}$. The activation enthalpy $\Delta \mathrm{H}^{\neq}$, Gibbs free energy $\Delta \mathrm{G}^{\neq}$and activation entropy $\Delta \mathrm{S}^{\neq}$ for the degradation process were also determined.
\end{abstract}

Keywords: Prunus spinosa L., anthocyanins, degradation kinetics

\section{INTRODUCTION}

At the present, there is a growing trend and interest in the nutrition quality of the consumed food, especially in the developed societies. Consumers do more and more regard food in relation to its health benefits, increasing their attention on food nutraceutical components. Fruits and vegetables are consumed as sources of bioactive compounds with a particularly positive

\footnotetext{
a Babeş-Bolyai University, Faculty of Chemistry and Chemical Engineering, 11 Arany Janos str., RO-400028, Cluj-Napoca, Romania

*Corresponding author: muntean@chem.ubbcluj.ro
} 
health impact. Berries, such as blackberry, blueberry, cranberry, strawberry, raspberry, are largely consumed for their delicious taste but also as rich sources of various disease-fighting compounds such as phenolics, flavonoids, anthocyanins, carotenoids, vitamins and minerals [1-3]. Extracts of most berries possess high antioxidant activity, acting effectively as free radical scavengers [4, 5]. Among phytocompounds which contribute to protection against degenerative diseases and against ageing processes, effects attributed to their antioxidant activity, anthocyanins play a significant role. These compounds are water soluble pigments, belonging to the flavonoids group, produced by plants as secondary metabolites, playing an important role in plant defence against different stress factors, such as UV radiation, pathogens, or plague [6].

Blackthorn (Prunus spinosa L.) is a perennial plant belonging to rose family (Rosaceae) which grows as a shrub and is native to Europe, western Asia and north-west Africa. Its fruits are bitter and astringent, with a poor commercial value, being less consumed raw but usually processed into jams, marmalades, juice, tea or macerated with sugar and alcohol to obtain a type of liquor [7]. Blackthorn (Prunus spinosa L.) has been used in ethno-botanic medicine for treatment of hypertension, of cough, as antispastic, diuretic, antiseptic, laxative or anti-inflammatory agent $[8,9]$.

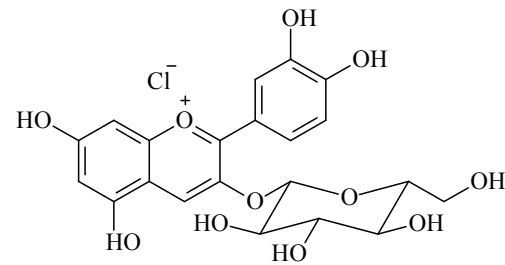

$\mathbf{a}$

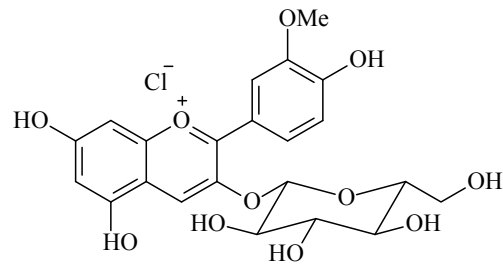

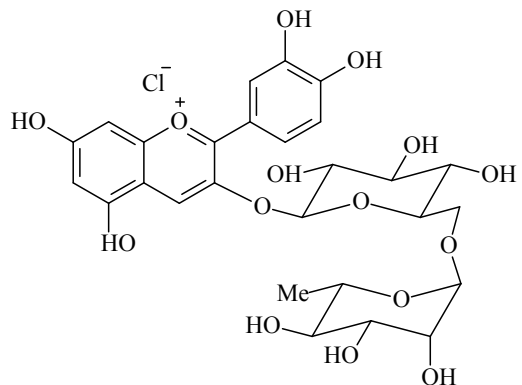

b

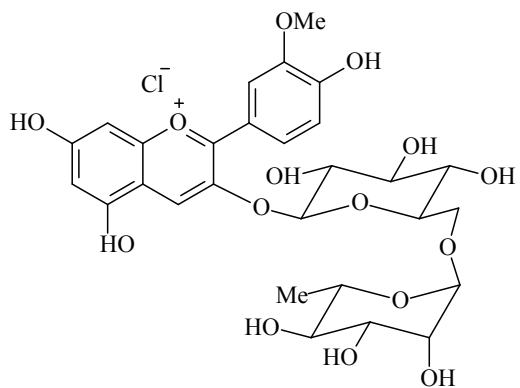

d

Figure 1. Chemical structures of blackthorn anthocyanins: a) cyanidin-3-glucoside; 402

b) cyanidin-3-rutinoside; c) peonidin-3-glucoside; d) peonidin-3-rutinoside. 
Apart from phytotherapy, blackthorn could also be an important source of colour compounds useful in the food industry. The anthocyanins from Prunus spinosa $\mathrm{L}$. fruits could be a healthy alternative to the toxic red dyes usually employed to colour food products. Deineka et al. [10] identified four anthocyanic compounds in blackthorn fruits, namely cyanidin-3-glucoside, cyanidin-3rutinoside, peonidin-3-glucoside and peonidin-3-rutinoside (Figure 1).

However, anthocyanins are not very stable compounds as they easily degrade during thermal processing, light exposure and storage, causing colour fainting or colour change of anthocyanin coloured foods. Thus, investigating the stability of these compounds in order to use them as health beneficial natural colorants is a matter of great concern. As a consequence, kinetic studies of anthocyanins degradation in various conditions, such as thermal exposure and storage, are very important for the food industry.

The aim of the present study was to investigate the thermal stability of anthocyanins isolated from blackthorn and to determine the kinetic and thermodynamic parameters of the degradation process of these compounds at various temperatures.

\section{RESULTS AND DISCUSSION}

The fruit extract obtained from Prunus spinosa L. fruits was investigated in order to determine its TAC (total anthocyanin content). The assessment of this parameter was realised by using a well known and widely applied method: the $\mathrm{pH}$ differential method of Giusti and Wrolstad [11]. It is based on the spectrophotometric determination of anthocyanin concentrations in a fruit extract at two different $\mathrm{pH}$ values ( 1 and 4.5 , respectively), by taking into account the structural dependence of anthocyanins molecules from the solution $\mathrm{pH}$ value. The red coloured flavylium cation is the predominant structural form of anthocyanins at $\mathrm{pH}=1$, while at $\mathrm{pH}=4.5$, the colourless carbinol predominates.

The TAC of the blackthorn fruit extract was calculated using equation (1) and the results were expressed as $\mathrm{mg}$ of cyanidine-3-glucoside (Cy-3-Glu) equivalents/ litre of extract:

$$
T A C=\frac{A \cdot M W \cdot D F \cdot 1000}{\varepsilon \cdot l}
$$

where: $A=$ absorbance, calculated as: (equation 2 )

$\mathrm{MW}=449.2 \mathrm{~g} / \mathrm{mol}$ (molecular weight of Cy-3-Glu)

$\mathrm{DF}=$ dilution factor 
$\mathrm{I}=$ path length $(1 \mathrm{~cm})$

$\varepsilon=26900 \mathrm{~L} / \mathrm{mol} / \mathrm{cm}$ (molar extinction coefficient of Cy-3-Glu) $1000=$ conversion factor from gram to milligram

$$
\left.A=\left(A_{p H 1.0}-A_{p H 4.5}\right){ }_{517 n m}-A_{p H 1.0}-A_{p H 4.5}\right) 700 \mathrm{~nm}
$$

The initial TAC of the blackthorn fruit extract was found to be $44.75 \mathrm{mg}$ Cy-3-Glu equivalents/ litre of extract.

The degradation of blackthorn anthocyanins over time was investigated at several temperatures $\left(2^{\circ} \mathrm{C}, 20^{\circ} \mathrm{C}\right.$ and $\left.75^{\circ} \mathrm{C}\right)$ by isothermal exposure of the fruit extract in darkness at these temperatures.

The anthocyanins' concentration decreased with exposure time at all investigated temperatures, indicating the degradation of these compounds. The loss of anthocyanins was more drastic at higher temperatures. After $24 \mathrm{~h}$ at $75^{\circ} \mathrm{C}$, only $22.68 \%$ of the original content of anthocyanins was present in the extract, while at $20^{\circ} \mathrm{C}$ after 12 days of storage $62.66 \%$ of the anthocyanins were still present in solution.

The kinetic parameters of the thermal degradation process of Blackthorn anthocyanins were determined using the linear regression of the natural logarithm (In) of the concentration at different process times (see Figures 2-4).

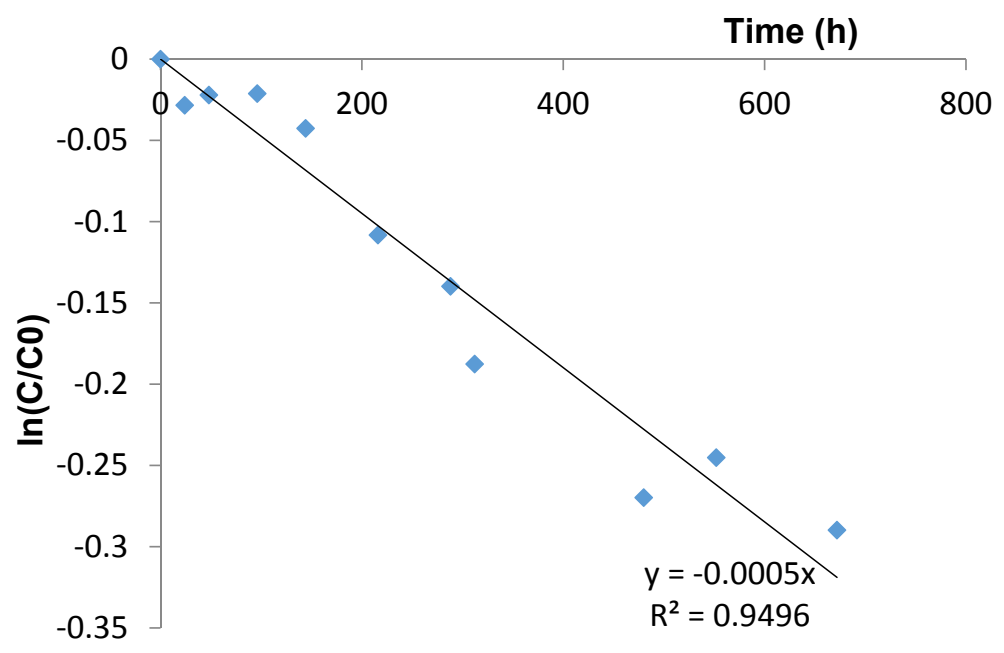

Figure 2. The degradation process of anthocyanins from Blackthorn fruits extract at $2^{\circ} \mathrm{C}$. 


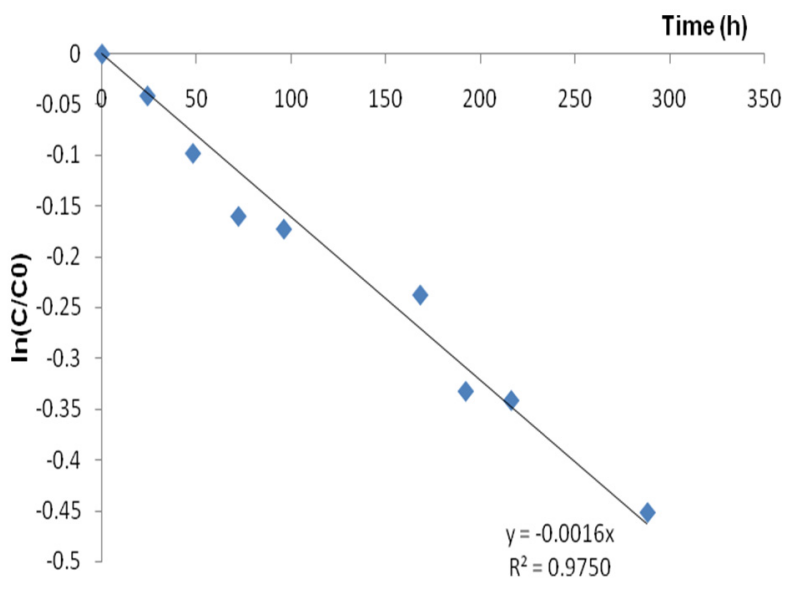

Figure 3. The degradation process of anthocyanins from Blackthorn fruits extract at $20^{\circ} \mathrm{C}$.

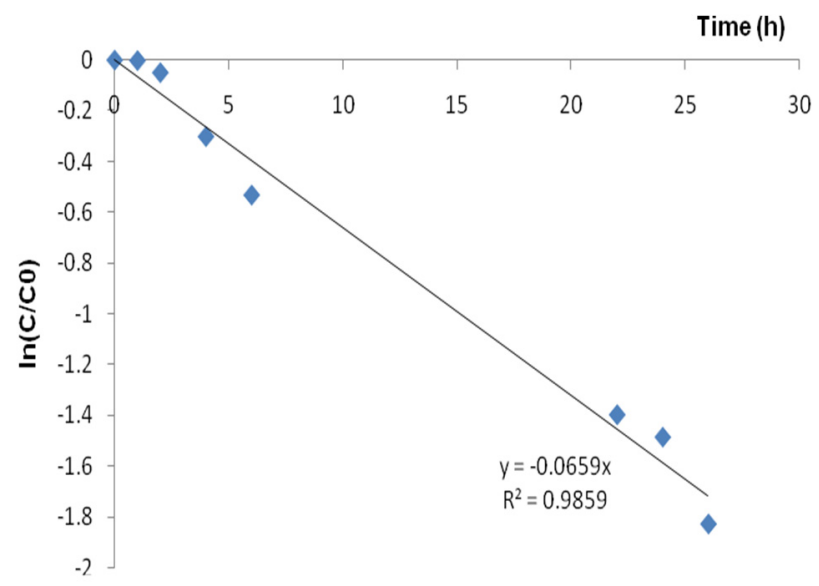

Figure 4. The degradation process of anthocyanins from Blackthorn fruits extract at $75^{\circ} \mathrm{C}$.

The obtained plots indicated a first order degradation kinetics at all temperatures, results in agreement with previous studies of anthocyanins thermal degradation in various extracts [12-16].

The first-order rate constants $k$ and the half-life $t_{1 / 2}$ values obtained for the degradation reactions of anthocyanins at each temperature are given in Table 1. 
Table 1. Kinetic parameters of the degradation process of blackthorn anthocyanins

\begin{tabular}{|c|c|c|}
\hline Temp. $\left({ }^{\circ} \mathbf{C}\right)$ & $\mathbf{k} \cdot \mathbf{1 0}^{\mathbf{4}}\left(\mathbf{h}^{-1}\right) \pm \mathbf{S D}^{*}$ & $\mathbf{t}_{1 / 2} \mathbf{( h )} \pm \mathbf{S D}^{*}$ \\
\hline 2 & $5 \pm 0.23$ & $1386 \pm 63.75$ \\
\hline 20 & $16 \pm 0.76$ & $433.1 \pm 20.57$ \\
\hline 75 & $659 \pm 26.09$ & $10.5 \pm 0.42$ \\
\hline
\end{tabular}

${ }^{*} \mathrm{SD}=$ Standard deviation

The high values of $R^{2}(>0.94)$ obtained for all cases indicated a good fit to the proposed first order reaction kinetics.

The kinetic rate constant values increased with temperature (being 132 fold higher at $75^{\circ} \mathrm{C}$ than at $2^{\circ} \mathrm{C}$, while increasing the temperature from $2^{\circ} \mathrm{C}$ to $20^{\circ} \mathrm{C}$ resulted in a 3 fold faster degradation). This confirms the strong influence of temperature on the degradation process of the anthocyanins. The calculated $t_{1 / 2}$ values obtained for Blackthorn anthocyanins at elevated temperature were higher than those reported for the degradation of anthocyanins from other sources. Kara et Erelebi [17] reported a half-life value of mulberry anthocyanins of $4.4 \mathrm{~h}$ at $70^{\circ} \mathrm{C}$ while Wang and $\mathrm{Xu}$ [18] obtained $8.8 \mathrm{~h}$ for blackberry anthocyanins degradation at the same temperature. Compared to these results, the degradation process of blackthorn anthocyanins was slower than that of mulberry or blackberry anthocyanins, blackthorn pigments presenting a greater heat stability.

In order to determine the effect of the temperature on the degradation process of blackthorn anthocyanins, the kinetic rate constants obtained at $2^{\circ} \mathrm{C}, 22^{\circ} \mathrm{C}$ and $75^{\circ} \mathrm{C}$ where fitted to the Arrhenius equation (3):

$$
k=K_{0} e_{-} E a / R T
$$

where: $\mathrm{k}=$ rate constant $\left(\mathrm{h}^{-1}\right)$

$\mathrm{K}_{0}=$ frequency factor $\left(\mathrm{h}^{-1}\right)$

$E_{a}=$ activation energy $(\mathrm{kJ} / \mathrm{mol})$

$\mathrm{R}=$ universal gas constant $(8.314 \mathrm{~J} / \mathrm{mol} / \mathrm{K})$

$\mathrm{T}=$ absolute temperature $(\mathrm{K})$

The calculated value of the activation energy of anthocyanins' degradation process was $53.96 \mathrm{~kJ} / \mathrm{mol}$.

The high Ea value determined for the blackthorn anthocyanins indicates that the investigated compounds are less susceptible to thermal degradation. Previous studies reported comparable Ea values for various fruits anthocyanins degradation: $58.55 \mathrm{~kJ} / \mathrm{mol}$ for Cornelian cherries [14], $66.37 \mathrm{~kJ} / \mathrm{mol}$ for blueberries [15] and $65.32 \mathrm{~kJ} / \mathrm{mol}$ for grape pomace [19]. 
The thermodynamic parameters of the anthocyanin degradation reaction are also determined, by means of equations (4), (5) and (6):

$$
\begin{aligned}
\Delta H^{\neq} & =E a-R \cdot T \\
\Delta G^{\neq} & =-R \cdot T \cdot \ln \left(\frac{k \cdot h}{k_{B} \cdot T}\right) \\
\Delta S^{\neq} & =\frac{\Delta H^{\neq}-\Delta G^{\neq}}{T}
\end{aligned}
$$

where: $\Delta \mathrm{H}^{\neq}=$activation enthalpy $(\mathrm{kJ} / \mathrm{mol})$

$\mathrm{Ea}=$ activation energy $(\mathrm{kJ} / \mathrm{mol})$

$\mathrm{R}=$ universal gas constant $(8.314 \mathrm{~J} / \mathrm{mol} / \mathrm{K})$

$\mathrm{T}=$ absolute temperature $(\mathrm{K})$

$\Delta \mathrm{G}^{\neq}=$Gibbs free energy of activation $(\mathrm{kJ} / \mathrm{mol})$

$\mathrm{k}=$ rate constant at temperature $\mathrm{T}$

$\mathrm{h}=6.6262 \cdot 10^{-34} \mathrm{Js}$ (Planck's constant)

$\mathrm{k}_{\mathrm{B}}=1.3806 \cdot 10^{-23} \mathrm{~J} / \mathrm{K}$ (Boltzmann's constant)

$\Delta \mathrm{S}^{\neq}=$activation entropy $(\mathrm{J} / \mathrm{molK})$

Table 2 presents the values of the activation enthalpy $\Delta \mathrm{H}^{\neq}$, activation entropy $\Delta S^{\neq}$and Gibbs free energy $\Delta \mathrm{G}^{\neq}$at the investigated temperatures.

Table 2. Thermodynamic parameters of blackthorn anthocyanins' thermal degradation

\begin{tabular}{|c|c|c|c|}
\hline Temp. $\left.\mathbf{(}^{\circ} \mathbf{C}\right)$ & $\begin{array}{c}\mathbf{\Delta H}^{\neq} \\
(\mathbf{k J / m o l})\end{array}$ & $\begin{array}{c}\mathbf{\Delta S}^{*} \\
(\mathbf{J} / \mathbf{m o l} . \mathbf{K})\end{array}$ & $\begin{array}{c}\Delta \mathbf{G}^{\neq} \\
(\mathbf{k J / m o l})\end{array}$ \\
\hline 2 & 51.67 & -51.45 & 65.82 \\
\hline 20 & 51.51 & -55.66 & 67.93 \\
\hline 75 & 51.07 & -53.98 & 69.85 \\
\hline
\end{tabular}

Relatively small values of activation $\Delta \mathrm{H}^{*}$ indicate that the formation of the activated complex is favorised as the energy barrier to achieve the transition state is low. As shown in Table 2, the activation enthalpy values were similar for all experimental conditions, varying between 51.07 and 51.67 $\mathrm{kJ} / \mathrm{mol}$. The positive sign of $\Delta \mathrm{H}^{\neq}$means that activation of the degradation is endothermic. 
The activation $\Delta S^{\neq}$values determined for the reaction investigated in this study ranged from -51.45 to $-53.98 \mathrm{~J} / \mathrm{molK}$, being all negative. The negative sign of the entropy indicates that the structural freedom of the transition state is lower than that of the reactants [20].

The positive activation $\Delta G^{\neq}$values suggest that the thermal anthocyanin degradation in the Blackthorn extract is a non-spontaneous reaction [21].

\section{CONCLUSIONS}

The present study investigated the thermal degradation of blackthorn anthocyanins, stored at various temperatures. The results clearly indicated that the degradation process followed first-order reaction kinetics. The first order rate constants ranged from $5 \cdot 10^{-4}$ to $6.59 \cdot 10^{-2} \mathrm{~h}^{-1}$, the degradation process being faster at elevated temperatures. The activation energy for the degradation process was determined to be of $53.96 \mathrm{~kJ} / \mathrm{mol}$. The thermodynamic parameters of the degradation process suggest that its activation is endothermic and nonspontaneous. Overall, blackthorn anthocyanins proved to be rather stable compared to pigments isolated from other sources, and hence may be successfully used as colorants in the food industry.

\section{EXPERIMENTAL SECTION}

\section{Chemicals and reagents}

All chemicals and reagents were purchased from Merck (Darmstadt, Germany), were of analytical grade and were used without further purification. A TYPDP1500 Water distiller (Techosklo LTD, Držkov, Czech Republic) was used to obtain the distilled water.

\section{Plant material} Romania.

Blackthorn fruits were harvested in October 2017 from Alba county,

\section{Extract preparation}

The extraction of the anthocyanins was obtained by mixing 20 grams of fresh crushed fruits with $50 \mathrm{~mL} 96 \%$ ethanol and stirred for 1 hour at ambient temperature. The mixture was filtered under reduced pressure and the filtrate was used to determine total anthocyanins concentration. 


\section{Determination of anthocyanin content}

Anthocyanins were quantified by using the $\mathrm{pH}$ differential method. The fruit extract was mixed with a $\mathrm{KCl}$ buffer solution $(0.025 \mathrm{M}, \mathrm{pH}=1)$ as well as with a $\mathrm{CH}_{3} \mathrm{COONa}$ solution $(0.4 \mathrm{M}, \mathrm{pH}=4.5)$ at a pre-established dilution factor of 8 . After 15 minutes in the dark, the absorbencies of each mixture were measured at 517 and $700 \mathrm{~nm}$ using an UV-VIS Perkin Elmer Lambda 25 double beam spectrophotometer. From the obtained absorbencies the total anthocyanins content was calculated and expressed as $\mathrm{mg} / 1$ liter extract of cyanidin-3-glucoside. All experiments were carried out in triplicate.

\section{Degradation studies}

The thermal degradation experiments were conducted at $2^{\circ} \mathrm{C}, 20^{\circ} \mathrm{C}$ and $75^{\circ} \mathrm{C}$, respectively.

Aliquots of $15 \mathrm{~mL}$ of blackthorn fruit extract were transferred in 3 hermetically sealed amber vials previously equilibrated in a thermostatic water bath at the desired temperatures. At different time intervals, samples were removed and rapidly cooled into an ice bath and the total anthocyanin content was determined as previously indicated. Data were fitted to the firstorder kinetic equations and the desired kinetic and thermodynamic parameters were calculated for each temperature.

\section{REFERENCES}

1. B. Moldovan, O. Ghic, L. David, C. Chişbora, Revista de Chimie, 2012, 63, 463.

2. B. Moldovan, L. David, Mini-Reviews in Organic Chemistry, 2017, 14(6), 489.

3. B. Moldovan, A. Popa, L. David, Journal of Applied Botany and Food Quality, 2016, 89, 208.

4. S. N. Jimenez-Garcia, R. G. Guevara-Gonzalez, R. Miranda-Lopez, A. A. Peregrino-Perez, I. Torres-Pacheco, M. A. Vazquez-Cruz, Food Research International, 2013, 54, 1195.

5. B. Moldovan, L. David, S. C. Man, Studia Universitatis "Babeş-Bolyai" Chemia, 2017, 62 (2 TOM II), 311.

6. A. Szajdek, E. J. Borowska, Plant Foods for Human Nutrition, 2008, 63, 147.

7. B. M. Ruiz-Rodriguez, B. de Ancos, C. Sanchez-Morena, V. Fernandez-Ruiz, M. C. Sanchez-Mata, M. Camara, J. Tardio, Fruits, 2014, 69, 61.

8. J. M. Velickovic, D. A. Costic, G. S. Stojanovic, S. S. Mitic, M. N. Mitic, S. S. Randelovic, A. S. Dordevic, Hemijska Industrija, 2014, 68, 297.

9. E. Sicora, M. I. Bieniek, B. Borczak, Acta Scientarum Polonorum, 2013, 12, 365. 10. V. I. Deineka, L. A. Deineka, A. A. Sirotnin, Chemistry of Natural Compounds, 2005, 41, 230. 
11. M.M. Giusti, R.E. Wrolstad, Current Protocols in Food Analytical Chemistry, Wiley, New York, 2001, F.1.2.1-F1.2.13.

12. B. Moldovan, R. Mintău, L. David, Studia Universitatis "Babeş-Bolyai" Chemia, 2015, 60 (1), 139.

13. B. Moldovan, L. David, R. Donca, C. Chişbora, Studia Universitatis "BabesBolyai", Chemia, 2011, 56, 189-194.

14. B. Moldovan, L. David, Molecules, 2014, 19, 8177.

15. A. Martynenko, Y. Chen, Journal of Food Engineering, 2016, 171, 44.

16. A. Sinela, N. Rawat, C. Mertz, N. Achir, H. Fulcrand, M. Dornier, Food Chemistry, 2017, 214, 234.

17. S. Kara, E.A. Ercelebi, Journal of Food Engineering, 2013, 116, 541.

18. W. D. Wang, S.Y. Xu, Journal of Food Engineering, 2007, 82, 271.

19. D.K. Mishra, K.D. Dolan, L. Yang, Journal of Food Science, 2008, 73, E9.

20. V.B. Vikram, M.N. Ramesh, S.G. Prapulla, Journal of Food Engineering, 2005, $69,31$.

21. G.D. Mercali, D.P. Jaeschke, I.C. Tessaro, L.D.F. Marczak, Food Chemistry, 2013, 136, 853. 